\title{
Enfermedad quística de la adventicia, arteria poplítea
}

\author{
Giancarlo Schiappacasse ${ }^{1}$, Camila De La Barra ${ }^{2}$, Fernando Ibáñez $^{3}$
}

Palabra clave: arteria poplítea; adventicia; mucinoso; diagnóstico diferencial; terapéutica.

\section{Resumen}

La enfermedad quística de la adventicia es una rara alteración de las arterias periféricas, caracterizada por la acumulación de contenido mucoso en la adventicia del vaso. Tiene predilección por la arteria poplitea, donde se localiza en cerca de $85 \%$ de los casos. La mayoría de los afectados son hombres entre los 40 y los 50 años de edad, que presentan claudicación intermitente de inicio brusco y rápida progresión, sin evidencia de enfermedad ateroesclerótica.

Se describe el caso un hombre de 57 años de edad en el que se diagnosticó esta entidad, con énfasis en las imágenes diagnósticas y el abordaje quirúrgico.

\section{Introducción}

La arterioesclerosis es la causa más frecuente de enfermedad arterial periférica ${ }^{1}$, condición que aumenta

Profesor asistente de Radiología, Departamento de Imágenes, Clínica Alemana de Santiago, Facultad de Medicina, Clínica Alemana-Universidad del Desarrollo, Santiago, Chile

2 Residente de Radiología, Facultad de Medicina, Clínica AlemanaUniversidad del Desarrollo, Santiago, Chile

3 Cirujano vascular, Facultad de Medicina, Clínica AlemanaUniversidad del Desarrollo, Santiago, Chile

Fecha de recibido: 12 de enero de 2016

Fecha de aprobación: 22 de abril de 2016

Citar como: Schiappacasse G, De La Barra C, Ibáñez F. Enfermedad quística de la adventicia, arteria poplítea. Rev Colomb Cir. 2017;32:56-60. progresivamente con la edad y con la presencia de factores de riesgo cardiovascular ${ }^{2}$. Sin embargo, existe un subgrupo de pacientes afectados a menor edad y sin factores de riesgo, en los que juegan un rol las causas no ateromatosas ${ }^{3}$. Entre estas, se encuentra la enfermedad quística de la adventicia ${ }^{1}$, entidad causada por una alteración de la adventicia de la arteria ${ }^{3}$ y descrita por primera vez en 1947 por Atkins y Key ${ }^{4}$.

El objetivo de este trabajo fue describir el caso de un paciente con esta condición, con enfoque en la evaluación imaginológica y el abordaje quirúrgico.

\section{Reporte del caso}

Se trata de un paciente de sexo masculino de 57 años de edad, con antecedentes de tabaquismo crónico (56 paquetes por año) suspendido 14 años atrás y dislipidemia. Consultó por claudicación con la caminata de 50 metros y paresia del pie derecho. En el estudio etiológico, la ecografía Doppler de la extremidad inferior demostró una lesión quística fusiforme de probable origen intraparietal, localizada en el aspecto posterior de la arteria poplítea, de 2,5 cm en su eje mayor, avascular al Doppler de color (figura 1).

Con estos hallazgos, se planteó como primera posibilidad una enfermedad quística de la adventicia de la arteria poplítea, con estenosis crítica secundaria. Posteriormente, una resonancia magnética (RM) de rodilla demostró alteraciones similares (figura 2). En la angiografía por RM de la región poplítea se observó, además, la zona de compresión y ausencia de flujo segmentario en la arteria poplítea (figura 3). 


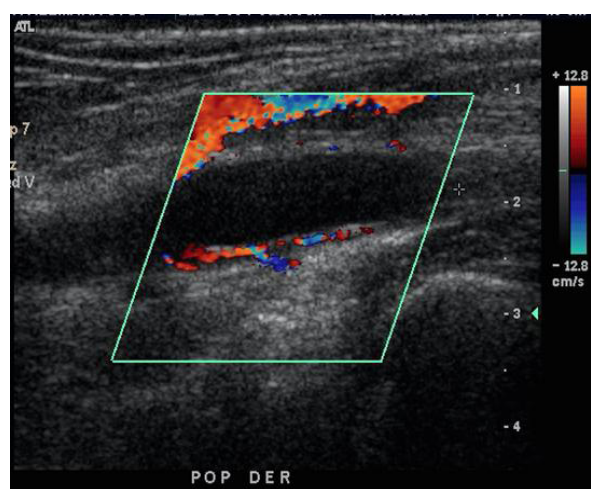

Figura 1. Ecografia Doppler de la extremidad inferior: se observa una lesión quística fusiforme localizada en el aspecto posterior de la pared de la arteria poplitea, de $2,5 \mathrm{~cm}$ en su eje mayor. No se demuestra flujo al estudio con Doppler a color.

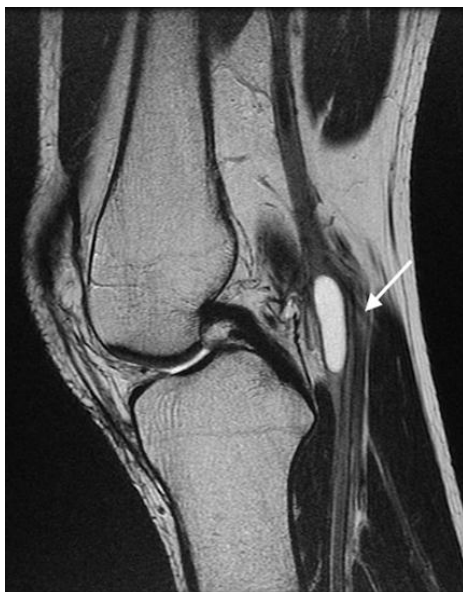

Figura 2. Resonancia magnética de rodilla, (imagen sagital en secuencia T2): se evidencia zona de compresión excéntrica de la arteria poplitea en una longitud de aproximadamente $2,5 \mathrm{~cm}$, determinada por la presencia de una imagen quística alargada de alta señal en T2 (flecha blanca).

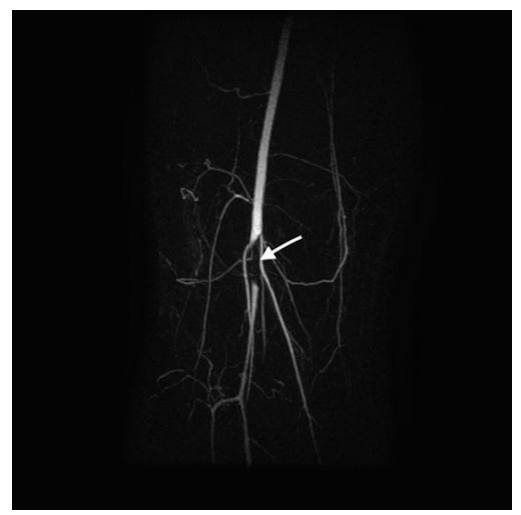

FIGURA 3. Angio-RM de la región poplitea (imagen coronal): se demuestra la zona de compresión y ausencia de flujo segmentario de la arteria poplitea en ese lugar (flecha blanca).

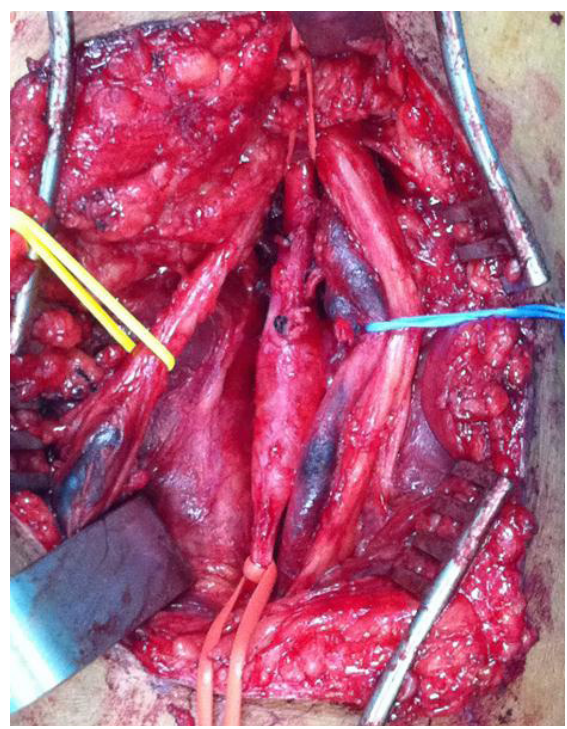

FIGURA 4. Imagen operatoria del abordaje posterior de la fosa poplitea: se observan la arteria poplitea rodeada por una cinta roja, la vena poplitea halada con una cinta azul y el nervio peroneo señalado con la cinta amarilla. Nótese la masa del gran quiste de la adventicia arterial.

Con la confirmación diagnóstica de enfermedad quística de la adventicia, se decidió intervenirlo quirúrgicamente. Se utilizó un abordaje posterior de la fosa poplítea (figura 4) que expuso la lesión quística dependiente de la pared arterial. Se resecó el segmento afectado (figura 5) y se reparó el defecto con intercalación de injerto autólogo de vena safena (figura 6). El paciente evolucionó favorablemente, sin complicaciones inmediatas. Acudió a control meses después de la cirugía, sin síntomas. Se practicó una angiografía por tomografía computadorizada (TC) de control, que demostró un adecuado flujo sanguíneo en el injerto (figura 7).

\section{Discusión}

La enfermedad quística de la adventicia es una afección infrecuente, que da cuenta del $0,1 \%$ de todas las enfermedades vasculares ${ }^{5}$. Se caracteriza por la acumulación de contenido mucoso en la adventicia del vaso ${ }^{6} \mathrm{y}$, comúnmente, se incluye en el diagnóstico diferencial de la claudicación en hombres jóvenes y de edad media sin factores de riesgo ${ }^{7}$. La mayoría de los casos compromete la arteria poplítea de forma unilateral ${ }^{8}$; sin embargo, se han descrito otras localizaciones, como las arterias axilar, braquial y radial ${ }^{9}$. 


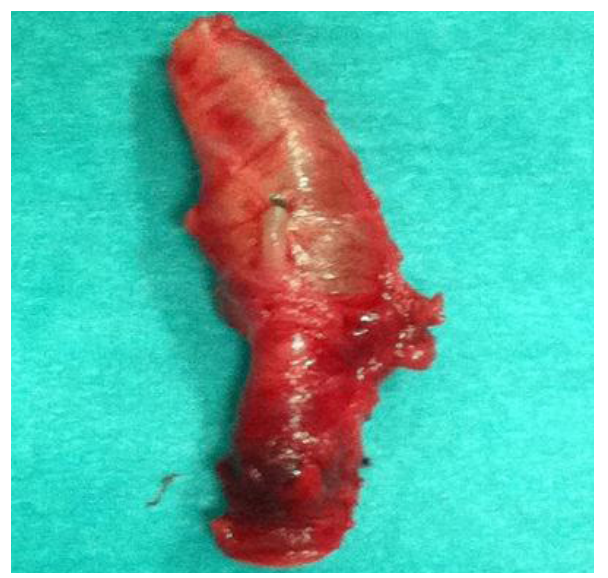

Figura 5. Pieza macroscópica de la arteria poplitea resecada con su quiste en la adventicia.

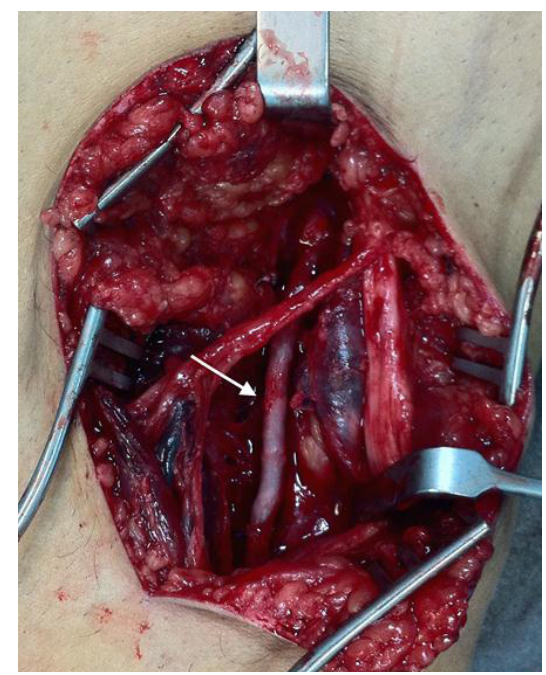

FIGURA 6. Imagen operatoria de la reparación arterial: se intercaló el injerto autólogo de vena safena (flecha blanca).

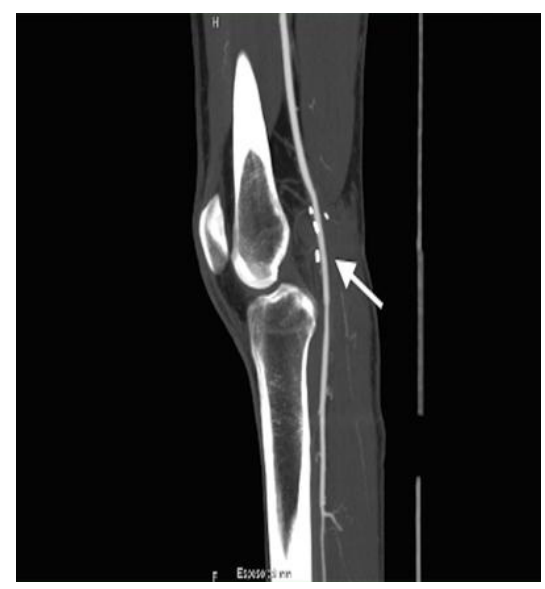

Figura 7. Angio-TC de control de las extremidades inferiores, reconstrucción sagital: se evidencia permeabilidad del injerto venoso (flecha blanca), el que muestra un adecuado calibre.
Afecta predominantemente al sexo masculino, con una razón de hombre a mujer de 15:1 ${ }^{9}$. La claudicación progresiva es la forma de presentación más frecuente; otros síntomas incluyen dolor y masa palpable de crecimiento lento ${ }^{10}$.

En el examen físico, los pacientes pueden tener pulsos periféricos normales, disminuidos o ausentes. Un signo patognomónico es la pérdida de los pulsos del pie con la flexión de rodilla (signo de Ishizawa) ${ }^{1}$.

La etiología de la enfermedad quística de la adventicia permanece incierta; sin embargo, cuatro teorías predominan en la literatura científica ${ }^{9}$. La teoría del trauma sugiere que el trauma menor repetitivo causaría degeneración quística de la adventicia ${ }^{6}$. Se ha descrito que la enfermedad quística de la adventicia es bioquímica e histológicamente similar al ganglión ${ }^{9}$. La teoría del ganglión sostiene que los quistes sinoviales se continúan a través de pequeñas ramas vasculares y, finalmente, se implantan en la adventicia ${ }^{6}$. La teoría de una afectación sistémica sostiene que puede ser parte de una alteración generalizada del tejido conjuntivo ${ }^{10}$. Finalmente, la teoría del desarrollo sugiere que se origina en la migración de células mesenquimatosas secretoras de mucina, provenientes de articulaciones cercanas, a la adventicia de los vasos en desarrollo ${ }^{5,6}$. Esta última es actualmente la más aceptada ${ }^{9}$.

Junto con la historia clínica, los estudios de imágenes son fundamentales para establecer el diagnóstico. La ecografía es un método útil en la evaluación de la esta enfermedad al estar ampliamente disponible, no ser invasiva y ser de bajo costo ${ }^{9}$. Permite visualizar el quiste como una estructura anecogénica o hipoecogénica en la pared del vaso, sin flujo demostrable en el modo Doppler, así como la estenosis arterial secundaria ${ }^{10}$.

La angiografía por sustracción digital se ha considerado el método de referencia para su evaluación ${ }^{9,10}$; sin embargo, actualmente ha sido reemplazada por la RM y la angio-RM ${ }^{10}$ que, además de demostrar la relación entre el quiste y la pared arterial, y la posible existencia de conexiones con la articulación adyacente ${ }^{10}$, proporciona orientación para la planificación quirúrgica ${ }^{8}$.

Los quistes pueden ser vistos en la pared de la arteria poplítea, pero también en sus ramas, como las arterias geniculadas ${ }^{8}$. Los quistes se observan hiperintensos en 
imágenes ponderadas en T2 (T2WI), mientras que, en imágenes ponderadas en T1 (T1WI), presentan intensidad de señal variable según las diferencias en su contenido mucoide ${ }^{8,10}$. En los quistes de mayor tamaño se pueden observar tabiques en su interior ${ }^{8}$. En secuencias contrastadas con gadolinio, no presentan realce o solo captación en anillo ${ }^{10}$.

Tanto la angiografía por sustracción digital como la angio-RM pueden demostrar una estenosis concéntrica (en forma de reloj de arena) o excéntrica (signo de la cimitarra) ${ }^{8}$, aunque también pueden ser normales o evidenciar oclusión arterial completa no específica ${ }^{8}$.

En el diagnóstico diferencial de la claudicación intermitente, se debe considerar la estenosis por ateromatosis, además de otras causas no ateromatosas, como el síndrome de compresión de la arteria poplítea 1, la embolia arterial, la compresión por hematoma y el quiste de Baker ${ }^{4}$. La historia clínica, en conjunto con los hallazgos imaginológicos, permite establecer el diagnóstico definitivo.

Se han descrito múltiples opciones terapéuticas, incluyendo la cirugía abierta o percutánea ${ }^{12}$. El drenaje del quiste permite la reexpansión de la arteria; sin embargo, este abordaje suele fracasar por la viscosidad del contenido y las altas tasas de recurrencia ${ }^{8,12}$. La angioplastia con balón no ha demostrado efectividad ${ }^{8,10}$. La escisión del quiste con preservación de la arteria suele ser el tratamiento preferido. No obstante, para muchos cirujanos vasculares el tratamiento de elección es la resección del quiste y del segmento arterial afectado, con interposición de un injerto autólogo de vena ${ }^{10}$. Esta aproximación, combinada con la ligadura de cualquier comunicación con la cavidad articular adyacente, reduce el riesgo de recurrencia ${ }^{8,10}$.

\section{Conclusión}

La enfermedad quística de la adventicia de la arteria poplítea es una causa infrecuente de isquemia de las extremidades inferiores que debe ser incluida en el diagnóstico diferencial de la claudicación intermitente en pacientes jóvenes y sin factores de riesgo cardiovascular. Su etiología permanece desconocida, siendo la teoría del desarrollo la más aceptada actualmente. La imaginología es clave para el diagnóstico. La cirugía es el tratamiento de elección.

\title{
Cystic disease of the adventitial layer of the popliteal artery
}

\begin{abstract}
Cystic adventitial disease is a rare vascular disorder of the peripheral arteries characterized by the collection of a mucinous substance inside the adventitia of the vessel. It has a predilection for the popliteal artery, being this localization about $85 \%$ of cases. Most of those affected are male between 40 to 50 years old, presenting with intermittent claudication of sudden onset and rapid progression without evidence of atherosclerotic disease. We describe the case of a 57 years old male who was diagnosed with this entity, with emphasis on the diagnostic imaging and surgical approach.
\end{abstract}

Key words: Popliteal artery; adventitia; mucinous; diagnosis, differential; therapeutics.

\section{Bibliografía}

1. Hasbún S, Tapia R, Avendaño G, Lahsen J, Sánchez C. Degeneración quística de la arteria poplítea. Presentación de caso clínico. Rev Med Chile. 2015;143:112-5.

2. Moreno L, Ramírez M, Triana C. Correlación diagnóstica, clínica y angiográfica de la enfermedad arterial periférica. Rev Col Cir Vasc. 2012;12:27-33.
3. Maestu R, Rainaudi P, Batista P, Carratu M. Enfermedad adventicia quística de la arteria poplítea como causa de claudicación intermitente. Artroscopia. 2015;22:21-2.

4. Sanchis J, Palmero J, Guijarro J, Gil J. Enfermedad quística adventicial de la arteria poplítea: a propósito de un caso. Radiología. 2008;50:531-3. 
5. Kawarai S, Fukasawa M, Kawahara Y. Adventitial cystic disease of the popliteal artery. Ann Vasc Dis. 2012;5:190-3.

6. Maged I, Turba U, Housseini A, Kern J, Kron I, Hagspiel K. High spatial resolution magnetic resonance imaging of cystic adventitial disease of the popliteal artery. J Vasc Surg. 2010;51:471-4.

7. Mino M, Garrigues D, Pierce D, Arko F. Cystic adventitial disease of the popliteal artery. J Vasc Surg. 2009;49:1324.

8. Holden A, Merrilees S, Mitchell N, Hill A. Magnetic resonance imaging of popliteal artery pathologies. Eur J Radiol. 2008;67:159-168.

9. Hernández M, Serrano F, Martínez I, González S, Hernando M, Saiz A, et al. Cystic adventitial degeneration of the popliteal artery: Report on 3 cases and review of the literature. Ann Vasc Surg. 2014;28:1062-9.
10. Loffroy R, Rao P, Krausé D, Steinmetz E. Use of 3.0-Tesla high spatial resolution magnetic resonance imaging for diagnosis and treatment of cystic adventitial disease of the popliteal artery. Ann Vasc Surg. 2011;25:385.e5-10.

11. Taurino M, Rizzo L, Stella N, Mastroddi M, Conteduca F, Maggiore $\mathrm{C}$, et al. Doppler ultrasonography and exercise testing in diagnosing a popliteal artery adventitial cyst. Cardiovasc Ultrasound. 2009;7:23.

12. Mertens R, Bergoeing M, Mariné L, Valdés F, Krämer A. Endovascular treatment of cystic adventitial disease of the popliteal artery. Ann Vasc Surg. 2013;27:1185.e1-3

Correspondencia: Camila De La Barra, MD

Correo electrónico: camidlb@gmail.com

Santiago, Chile 